\title{
RISK DIVERSIFICATION BETWEEN STOCK MARKETS IN GERMANY AND BOSNIA AND HERZEGOVINA
}

Azra Zaimović, Almira Arnaut Berilo*

\section{Abstract}

The integration of global equity markets has been a well-studied topic in the last few decades, particularly after stock market crashes. Most studies have focused on developed markets such as the US, Western Europe and Japan. The findings were that the degree of international co-movements among stock prices has substantially increased in the postcrash regime. In this paper we research the co-movements of German and Bosnian stock markets during and after the recent economic and financial crisis.

International market integration means that assets of equal risk provide the same expected returns across integrated markets. This means fewer opportunities for risk diversification if the markets are integrated. It is also believed that stock market indices of integrated markets move together over the long run with the possibility of short-run divergence. There is considerable academic research on the benefits of international diversification. Investors who buy stocks in domestic as well in foreign markets seek to reduce risk through international diversification. The risk reduction takes place if the various markets are not perfectly correlated. The increasing correlation among markets during and after the crises has restricted the scope for international diversification.

International stock market linkages are the subject of extensive research due to rapid capital flows between countries because of financial deregulation, lower transaction and information costs, and the potential benefits from international diversification. Most stock markets in the world tend to move together, in the same direction, implying positive correlation. In and after crises they tend to move together even more strongly. Thus, this paper aims to research if there are any diversification opportunities by spreading out investments across developed and underdeveloped capital markets.

This research attempts to examine the scope of international diversification between German and Bosnian equity markets during the 6-year period from 2006 to 2011. We test the hypothesis of whether there are any risk diversification possibilities by spreading out the investments between German and Bosnian equity markets. In order to determine the mean-variance efficiency of portfolios we use the method of convex (quadratic and linear) programming. The hypothesis is tested with the Markowitz portfolio optimization method using our own software.

The results of this research might enhance the efficiency of portfolio management for both types of capital market under analysis, and prove especially useful for institutional investors such as investment funds.

Keywords: Risk Diversification, German and Bosnian Capital Markets, Markowitz method

JEL Classification: G11, G32

Azra Zaimović, Ph.D.

Assistant Professor of Finance

Univerity of Sarajevo

School of Economics and Business

azra.zaimovic@efsa.unsa.ba

\section{Almira Arnaut-Berilo}

Assistant Professor of Quantitative Economy University of Sarajevo

School of Economics and Business

almira.arnaut@efsa.unsa.ba* 


\section{INTRODUCTION}

Investors prefer holding portfolios of securities rather than a single security due to a risk-reduction effect called risk diversification. In addition to providing arbitrage opportunities, diversification is often called "the free lunch in finance."

International stock market linkages are the subject of extensive research for the following reasons: (1) the rapid flow of capital among countries due to financial deregulation, ${ }^{1}$ (2) information availability, (3) the reduction of transaction costs, and (4) the potential gains from international diversification of investment portfolios (In, Kim and Yoon, 2002). Most stock markets in the world tend to move together, in the same direction, implying positive correlation. However, the increasing correlations among developed and emerging markets have restricted the scope of international diversification (Srivastava, 2007).

Thus, this paper aims to research if there are any diversification opportunities between two European, and in many aspects different equity markets: those of Germany and Bosnia \& Herzegovina. This research examines the scope of international diversification over a six-year period before, during and after the recent crisis, from 2006 to 2011 . We test the hypothesis of whether there are any risk diversification possibilities by spreading out investments between German and Bosnian equity markets. The hypothesis is tested by statistical methods and with the Markowitz portfolio optimization process (Markowitz, 1952, 1991). The research results might allow more efficient securities portfolio management on European capital markets.

This paper is organized into five sections, including an introduction. Section 2 outlines the theoretical background and methodology, Section 3 deals with data, Section 4 presents the results, and in Section 5 we conclude the study.

\section{THEORETICAL AND METHODOLOGICAL FRAMEWORK}

The integration of global equity markets has been a well-studied topic in the last two and a half decades, particularly since the October 1987 stock market crash. Most studies are conducted for developed markets like the US, Western Europe and Japan. The findings were that the degree of international co-movements among stock prices has substantially increased in the post-crash regime (Arshanapalli and Doukas, 1993). After the Asian crisis, the literature started focusing on

1 The global financial and economic crisis has revealed the need for new regulation of financial markets and banks. emerging Asian markets as well. The recent financial and economic crisis has renewed the topic of capital market co-movements.

International market integration has several definitions. One states that assets of equal risk provide the same expected returns across integrated markets. This means that there are fewer opportunities for risk diversification if the markets are integrated. The second definition states that in integrated markets national stock market indices move together over the long run with the possibility of short run divergence.

Vizek and Dadić (2005) researched multilateral integration between the emerging markets of Central and Eastern Europe (CEE) and the German equity market for the period from January 1997 till June 2005. The authors find that the equity markets of Croatia and other CEE emerging equity markets, namely those of Poland, the Czech Republic, Slovenia and Hungary, are multilaterally integrated. In addition, their results indicate multilateral integration between the CEE equity markets and the German equity market. When analyzing Croatian and German equity markets alone, they find no evidence of bilateral integration.

Zaimović and Delalić (2010) investigate the risk diversification possibilities of the four West Balkan capital markets: the Sarajevo, Banja Luka, Zagreb and Belgrade Stock Exchanges. By analyzing the six main stock market indices in a 34-month period, from 2006 till 2008, they found a low to medium positive statistically significant correlation between indices returns pairs. The equally weighted portfolio of three index fund stocks would have a very good standard deviation - mean trade-off, lying almost on the efficient frontier. This study encourages the creation of index replicating funds in the analyzed markets.

Within the theoretical context of market integration, international stock market linkages and interdependence form a cornerstone of modern portfolio theory, especially in relation to asset diversification. This theory suggests that investors diversify their assets across national borders as long as stock returns in other markets are less than perfectly correlated with those of the domestic market (Masih and Masih, 1997).

Financial integration between equity markets can be assessed by a different methodology. Fratzschner (2001) used uncovered interest parity, Korajczyk (1995) used multifactor Arbitrage Pricing Theory, Bekaert and Harvey (1995) and Dumas and Solnik (1995) used the Capital Asset Pricing Model. Co-integration analysis is used to test the stability of long run relationship across financial markets (Dickinson, 2000, Vizek and Tadić, 2005).

Risk diversification has two basic sources: one concept was developed by Markowitz (1952) and another 
developed by Sharpe (1964). Markowitz introduced the notion of a (mean-variance) efficient portfolio that (1) provides minimum variance for a given expected return or (2) provides maximum expected return for a given variance. Diversifying risk by selecting weakly correlated securities implies that the decision is made based on information about standard deviation and correlation between securities' returns. This diversification is called Markowitz or efficient diversification, because Markowitz was the first who developed the procedure for calculating efficient portfolios.

Sharpe finds that one can reduce the risk of a portfolio just by adding randomly selected securities in a portfolio, in such a way that all the securities have the same but small weights. Through this procedure, unsystematic risk is diversified, while systematic risk becomes the only risk to be rewarded on the capital market. This approach does not explicitly assume that the securities' returns are uncorrelated. Sharpe calls this diversification random diversification, essentially because an investor does not have to know information about the standard deviation and correlation between securities' returns.

In this paper we adopted Markowitz's methodology to demonstrate the diversification possibilities on the selected capital markets. The efficient frontier of any possible portfolio of stocks, regardless of the number of stocks in the portfolio, lies between the portfolio with the minimum standard deviation (also minimum variance) and the portfolio with the maximum rate of return (mean). The portfolio with the maximum rate of return is the upper, final point on the efficient frontier. If the short sales are not allowed, the final portfolio (up on the right) in the efficient frontier will always be represented by only the stock with the highest return in the portfolio.

The classical Markowitz portfolio model is used to determine the efficient portfolios returns

$$
\bar{R}_{p}=\sum_{i=1}^{n} \bar{R}_{i} x_{i}
$$

and portfolio variances

$$
\sigma_{p}^{2}=\sum_{j=1}^{n} \sum_{i=1}^{n} x_{j} x_{i} \operatorname{Cov}\left(R_{i}, R_{j}\right)
$$

if portfolio investments satisfy the constraints

$$
\begin{aligned}
& \sum_{i=1}^{n} x_{i}=1 \\
& x_{i} \geq 0, \quad i=\overline{1, n}
\end{aligned}
$$

There are two types of constraints in this model. The first constraint appears in all models, and it requires that the sum of all investment weights be 1 , with investments $x_{i}(i=\overline{1, n})$ defined as portions of money invested in each individual security in a portfolio. The other set of constraints requires that the investment be non-negative, which means that there is no lending or short-sells.

The mean-variance combination of securities is efficient if there are no other portfolios with the same return and lower variance, or the same variance and higher return. In determining the efficient combination of a set of securities (or in efficient portfolio determination) several optimization problems are detected. First, in this model the set of possible portfolios is limited, where the minimum limit is represented by the portfolio with the lowest possible variance, and the maximum limit being the portfolio with the highest possible return. In addition, in the very definition of the efficient portfolio we can see that for every rate of return the lowest variance portfolio has to be determined, and for every variance, the highest return portfolio has to be determined.

Let us assume an investor considers investing in a portfolio, with a given value of expected return on investment $E$, and is interested in the lowest variance with which the return can be achieved. The optimization model is formed as:

$$
\begin{gathered}
\min _{\mathbf{x}} \sigma^{2}=\sum_{i=1}^{n} \sum_{j=1}^{n} \sigma_{\ddot{y}} x_{i} x_{j} \\
\sum_{i=1}^{n} x_{i}=1 \\
\sum_{i=1}^{n} \bar{R}_{i} \cdot x_{i}=E \\
x_{i} \geq 0, \quad i=\overline{1, n}
\end{gathered}
$$

where the constant $E$ has to be between the efficient portfolio with the lowest variance, $\bar{R}_{\min }$ and the efficient portfolio with the highest expected return, $\bar{R}_{\max }$. If the following is true $E>\bar{R}_{\max }$, model (4) would be unsolvable, and if $E<\bar{R}_{\min }$ then the solution to the system (4) would not be an element of the efficient set. As a result of applying the complementary algorithm (used for solving the quadratic programming model 4) we will get the investment vectors that provide the absolutely minimum portfolio return variance $\sigma_{\min }^{2}$ with the pre-set return $E$.

By choosing a randomly expected return of investment in the range $\bar{R}_{\min } \leq E \leq \bar{R}_{\max }$ we can determine the efficient set of observed security. 
Figure 1: Set of possible portfolios and Capital Market Line

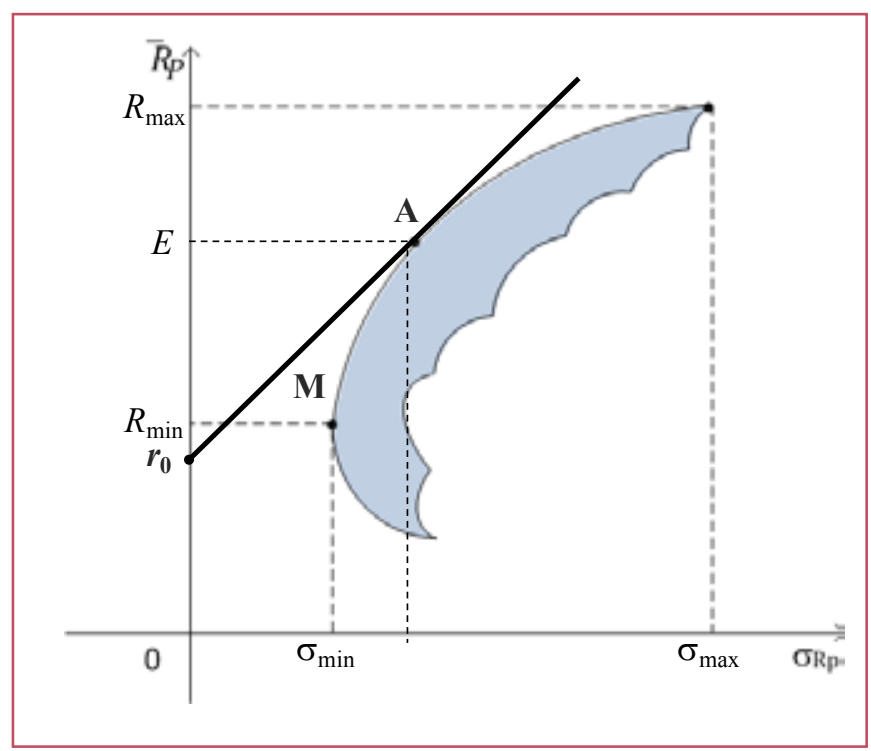

We have selected two characteristic portfolios, the minimum variance portfolio and the portfolio with the best risk-return trade-off (maximum Sharpe ratio). In Figure 1, these two portfolios are marked as $\mathrm{M}$ and A, respectively.

\section{DATA}

In order to measure diversification possibilities and asset behavior in the German and Bosnian equity markets, we have determined and analyzed the efficient portfolios formed from selected stocks from the Frankfurt Stock Exchange (FSE) and the Sarajevo Stock Exchange (SASE), both apart and together. Input data for mean-variance (MV) analysis are the last stock weekly prices sourced from the official webpage of the $\mathrm{SASE}^{2}$ for the Bosnian market and from the Yahoo Finance webpage ${ }^{3}$ for stocks from the German market.

The time interval for diversification tests was determined by the global economic crisis and its effects on diversification possibilities on these two markets. The additional criterion was the liquidity of stocks on the SASE. In 2006 the SASE introduced the Multi Fixing Trading Schedule (MFTS) for the most liquid stocks. In the same year turnover on SASE was larger than EUR 332 million (BAM 650 million), which is why we have chosen the 2006 year for the beginning of our analysis. Earlier periods on the SASE were characterized by low liquidity, irregular trading activity and a small number of traded stocks. Thus, we have observed

2 Sarajevo Stock Exchange: www.sase.ba (accessed in October 2011)

3 Yahoo Finance: www.yahoofinance.com (accessed in October 2011) stocks in the period from the $3^{\text {rd }}$ of January 2006 till the $1^{\text {st }}$ of Jun 2011 . Stock returns were calculated on a weekly basis, based on capital gain/loss, not including dividend yield.

According to the research goals we have selected stocks from both equity markets that represent overall market movements. Forty-three stocks have been selected from the SASE. ${ }^{4}$ These stocks have been traded by the MFTS algorithm in the official market and in the SASE primary free market. The overall proportion of these 43 stocks in all market turnovers in the last three years (2009, 2010 and 2011) is 51.8\%. Moreover, the proportion of the number of transactions is even higher, $77.85 \%$.

By analyzing the collected data we realized that some stocks had less than 20 weekly trading data in the observed period. These stocks have been removed from the sample. In the end 22 stocks from the SASE represented the Bosnian equity market. $^{5}$

Since the German equity market is large, we have selected 50 stocks from 9 different industries, which adequately represent the German market. There is much evidence that the risk of a portfolio of 40 even randomly selected stocks consists only of market (diversifiable) risk, (Sharpe, 1964).

According to the aim of this research, we have divided the observed period into three time samples:

- January 2006 - January 2008, the period before the crisis,

- January 2008 - January 2010, the period during the crisis,

- June 2009 - June 2011, the period after the crisis.

There is a 6 month overlapping period in 2009, due to the fact that the German economy started recovering in 2009. In addition, in this way we managed to divide the 5.5 year-long period into three equally long sub-periods; each sample consists of 104 data.

\section{RESULTS}

In order to test the diversification possibilities between the German and Bosnian equity markets in the observed sub-periods, we form MV efficient portfolios of sample stocks from the FSE and test the effects of

4 We found it inappropriate to use only stocks included in indices from the SASE in our analysis because of the meanvariance inefficiency of indices found in previous studies (Arnaut-Berilo, Zaimović, 2012).

5 The missing data were supplemented by the last occurring price. The stocks with sufficient liquidity had normally distributed returns, at the same time. 
spreading out the investments to the sample stocks from the SASE in Figures 2, 3 and 4.

Figure 2: Efficient portfolios in pre-crisis period

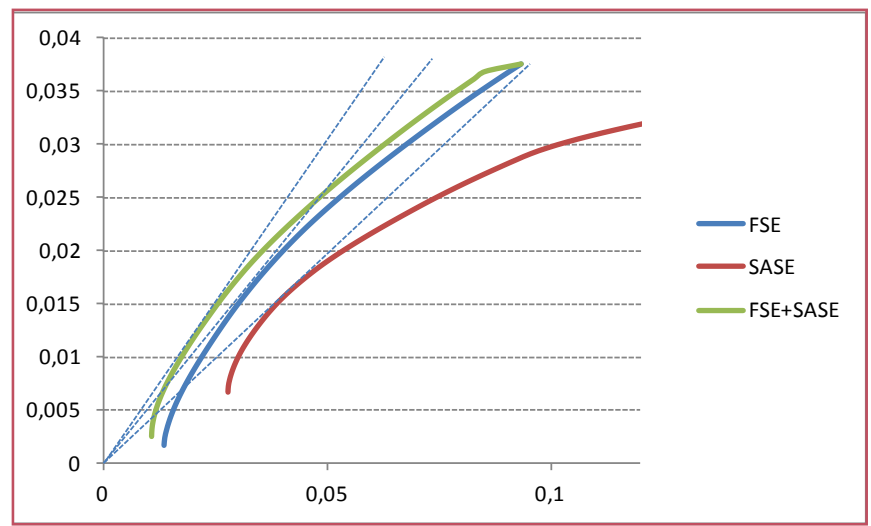

Source: Authors from the official stock exchanges databases, using own portfolio optimization software

We use Sharpe ratio (SR) in measuring efficient portfolio performances, assuming that the risk free rate is zero ${ }^{6}$, i.e. the capital market line drawn from the coordinate origin, (0.0). In addition to the graphical interpretation, where we see the efficient lines shift, we have determined the structure of minimum variance portfolios and the structure of portfolios with a minimum value of coefficient of variation ${ }^{7}(\mathrm{CV})$. The last portfolios are highlighted as the portfolios with the smallest dispersion from the expected value. In addition, these portfolios show the change of the efficient frontier curvature.

Figure 3: Efficient portfolios in crisis period

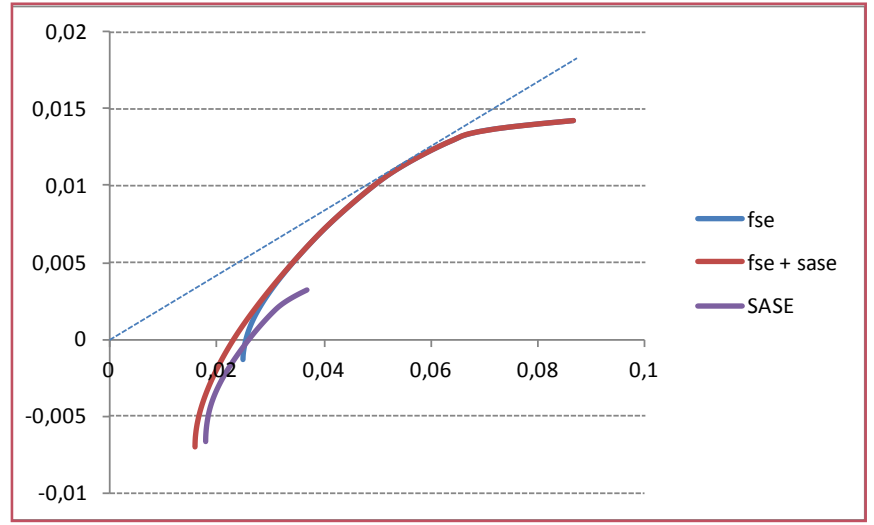

Source: Authors from the official stock exchanges databases, using own portfolio optimization software

6 . Weekly risk-free rates in observed periods are very low, especially in and after the crisis.

7 Portfolio with minimum value of CV has the steepest $\mathrm{SR}$, if the capital market line is drawn from the coordinate origin.
Our results show that the minimum variance of created portfolios is reduced in the case of combining the German with the Bosnian sample stocks in all three sub-periods. In addition, we get more dominant efficient frontiers in the pre-crisis and after-crisis periods.

Figure 4: Efficient portfolios in the post-crisis period

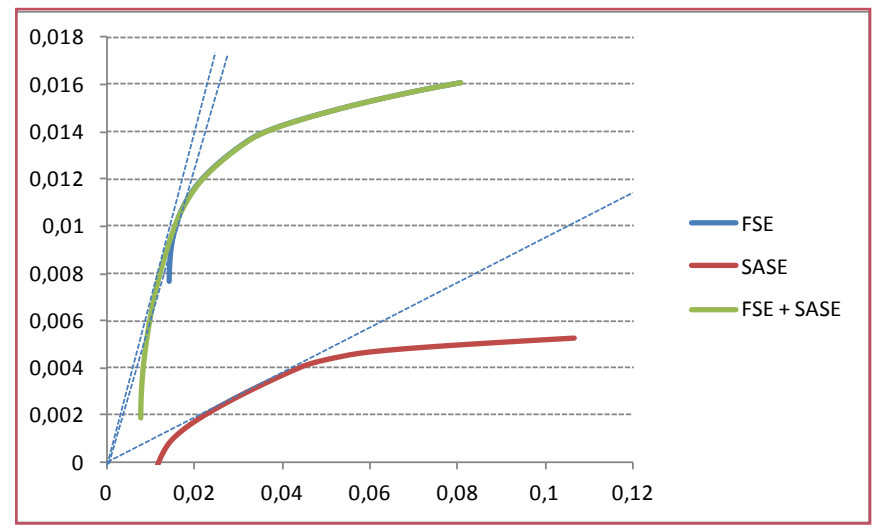

Source: Authors from the official stock exchanges databases, using own portfolio optimization software

In Table 1 we present the minimum variance portfolio characteristic values in all three sub-periods. In addition, we present characteristic values of portfolios with the best risk-return trade-off in Table $2 .{ }^{8}$

We note that in the pre-crisis period there is a benefit in expanding investments from the German capital market to the Bosnian. The minimum portfolio risk decreases from $1.36 \%$ to $1.08 \%$ if we spread out the investments to $78 \%$ (FSE) versus $22 \%$ (SASE). The Sharpe ratio of best performing portfolio increases from 0.50 to 0.58 .

We found no evidence of diversification possibilities in the crisis period. In this sub-period Bosnian stocks are not included in the optimal portfolio (the portfolio with the steepest Sharpe ratio). Based on this, as well as based on the analysis of Figure 3, we can conclude that the Bosnian market was more affected by the global crisis than the German.

As we can see from the Figure 4 and from Tables 1 and 2 , in the post-crisis period the minimum portfolio risk on FSE decreases from $1.43 \%$ to $0.8 \%$ if we spread out our investment between the German (34\%) and Bosnian markets $(66 \%)$, but portfolio performance is lower. If we spread out our investment between the German (70.63\%) and Bosnian markets (29.37\%) the best performing portfolio has the Sharpe ratio of 0.66 and we are able to reduce the risk of our investments.

By comparing the results of the pre- and post-crisis

8 The portfolio compositions of minimum variance portfolios in all sub-periods are available from the authors. 
Table 1. Min variance portfolio in observed periods

\begin{tabular}{|c|c|c|c|c|}
\hline $\begin{array}{l}\text { Minimum Variance } \\
\text { Portfolio in pre crisis period }\end{array}$ & FSE & \multicolumn{3}{|c|}{ FSE and SASE } \\
\hline Return & 0.001758 & 0.002452 & FSE portion & $77.90 \%$ \\
\hline Risk & 0.013584 & 0.010826 & SASE portion & $22.10 \%$ \\
\hline Sharpe Ratio & 0.129414 & 0.226512 & & \\
\hline $\begin{array}{l}\text { Minimum Variance } \\
\text { Portfolio in crisis period }\end{array}$ & FSE & \multicolumn{3}{|c|}{ FSE and SASE } \\
\hline Return & -0.0013 & -0.007073 & FSE portion & $34.70 \%$ \\
\hline Risk & 0.025019 & 0.015952 & SASE portion & $65.30 \%$ \\
\hline Sharpe Ratio & $\mathrm{N} / \mathrm{A}$ & $\mathrm{N} / \mathrm{A}$ & & \\
\hline $\begin{array}{l}\text { Minimum Variance } \\
\text { Portfolio in post-crisis period }\end{array}$ & FSE & \multicolumn{3}{|c|}{ FSE and SASE } \\
\hline Return & 0.007661 & 0.001899 & FSE portion & $34.10 \%$ \\
\hline Risk & 0.014398 & 0.007749 & SASE portion & $65.90 \%$ \\
\hline Sharpe Ratio & 0.532099 & 0.245117 & & \\
\hline
\end{tabular}

Source: Authors

Table 2. Characteristic values of portfolios with the highest Sharpe ratio in the observed periods

\begin{tabular}{|c|c|c|c|c|}
\hline Max Sharpe ratio & FSE & \multicolumn{3}{|c|}{ FSE and SASE } \\
\hline Return & 0.017477 & 0.014362 & FSE portion & $63.56 \%$ \\
\hline Risk & 0.034846 & 0.024622 & SASE portion & $36.44 \%$ \\
\hline Sharpe Ratio & 0.501540 & 0.58332 & & \\
\hline Max Sharpe ratio & FSE & \multicolumn{3}{|c|}{ FSE and SASE } \\
\hline Return & 0.011208 & 0.011208 & FSE portion & $100 \%$ \\
\hline Risk & 0.054559 & 0.054559 & SASE portion & $0 \%$ \\
\hline Sharpe Ratio & 0.205423 & 0.205423 & & \\
\hline Max Sharpe ratio & FSE & \multicolumn{3}{|c|}{ FSE and SASE } \\
\hline Return & 0.010014 & 0.008415 & FSE portion & $70.63 \%$ \\
\hline Risk & 0.015924 & 0.01275 & SASE portion & $29.37 \%$ \\
\hline Sharpe Ratio & 0.628819 & 0.659961 & & \\
\hline
\end{tabular}

Source: Authors

periods we find different diversification effects. The largest efficient frontier shift is observed in the precrisis period, when both markets obtained similar MV efficiency.

In the pre-crisis period the minimum variance portfolio also provided a better Sharpe ratio than the minimum variance portfolio of FSE stocks, in contrast to the post-crisis period when the minimum variance portfolio (consisting majorly of SASE stocks) has a lower Sharpe ratio than the minimum variance portfolio of FSE stocks. Moreover, SASE stocks participate with $29.37 \%$ in the portfolio with the steepest Sharpe ratio, created of stocks from both markets as shown in Table 2.

Sharpe ratio is the steepest in the post-crisis period compared to the pre-crisis and crisis periods; during the recovery most stocks tend to perform better. 


\section{CONCLUSIONS}

We have analyzed German and Bosnian equity markets' diversification opportunities before, during and after the global financial and economic crisis. In general, the German equity market is more meanvariance efficient than the Bosnian. The German market, as a mature market, has lower market risk in all of the observed sub-periods, i.e. efficient frontiers are situated more north-west, especially in the post-crisis period. We used Sharpe ratio as a measure of portfolio performance. Based on this measure we find that market risk in the German market ranges from 3.49\% in the pre-crisis period, $5.55 \%$ in the crisis-period to $1.59 \%$ in the post-crisis period, on a weekly basis.

International diversification among analyzed markets brings additional risk reduction. By spreading out investments between the German and Bosnian markets, portfolio risk decreases in the pre-crisis and postcrisis periods. The best risk-return trade-off can be found in the post-crisis period; the minimum variance portfolio's Sharpe ratio is 0.63 , while the best performing portfolio has a Sharpe ratio of 0.66 . As expected, in the recovery period the expected returns increase.

We find that the recent crisis has affected the Bosnian market much more strongly than the German market. In the crisis, the diversification effects among analyzed markets are negligible, i.e. the German market performed much better. The lack of diversification during the crisis is in our opinion less due to the high integration between analyzed markets than the underperformance of the Bosnian equity market.

Frontier equity markets should be seen as an attractive supplement to investments in mature and developed markets. We found evidence of benefits from international diversification among the German and Bosnian equity markets in the pre- and post-crisis periods.

\section{REFERENCES}

Arnaut-Berilo, A., Zaimović, A. 2012. "How efficient are Bosnian stock market indices?" Eastern European Economics Journal, M. E. Sharpe, 50 (1): 26-45.

Arshanapalli, B., Doukas, J. 1993. “International Stock Market Linkages: Evidence of Pre- and Post-October 1987 Period" Journal of Banking \& Finance, 17 (1): 193-208.

Bekaert, G., Harver, C. R. 1995. "Time-varying world market integration" The Journal of Finance, 50 (2): 403-444.

Dickinson, D. G. 2000. "Stock Market Integration and Macroeconomic Fundamentals: An Empirical Analysis", Applied Financial Economics, 10 (3): 261-276.

Dumas, B., Solnik, B. 1995. "The World Price of Foreign Exchange Risk", Journal of Finance, 50 (2): 445-479.

Fratzscher, M. 2001. "Financial Market Integration in Europe: on the Effects of EMU on Stock Markets", Working Paper 48, European Central Bank

In, F., Kim, S., Yoon, J. H. 2002. "International Stock Market Linkages: Evidence from the Asian Financial Crisis", Journal of Emerging Market Finance, 1: 1-29.

Korajezyk, R. 1995. "A Measure of Stock Market Integration for Developed and Emerging Markets", Policy Research Working Paper 1482, World Bank

Markowitz, H. 1952. "Portfolio Selection", Journal of Finance 7 (1): 77-91.

Markowitz, H. M. 1991. Portfolio Selection, Blackwell Publishing

Masih, A. M. M., Masih, R. 1997."A Comparative Analysis of the Propagation of Stock Market Fluctuations in Alternative Models of Dynamic Causal Linkages", Applied Financial Economics, 7 (1): 59-74.

Sharpe, W. F. 1964. "Capital Asset Prices: A Theory of Market Equilibrium under Conditions of Risk", The Journal of Finance, 19 (3): 425-442.

Srivastava, A. 2007. "Cointegration of Asian Markets with US Markets: International Diversification Perspectives", Global Business Review, 8: 251-265.

Vizek, M., Dadić, T. 2006. "Integration of Croatian, CEE and EU Equity Markets: Cointegration Approach", Ekonomski pregled, 57 (9-10): 631-646.

Zaimović, A., Delalić, A. 2010. "Possibilities of Risk Diversification in Regional Stock Exchanges", Ekonomska istraživanja 23 (1): 30-46.

Internet pages:

(Sarajevo Stock Exchange, http://www.sase.ba, October 2011)

(Frankfurt Stock Exchange, http://deutsche-boerse.com, October 2011)

(Yahoo Finance, http://finance.yahoo.com, October 2011) 